\title{
Investigating the Digital Addiction Level of the University Students According to Their Purposes for Using Digital Tools
}

\author{
Ahmet Kesici ${ }^{1, *}$, Nazenin Fidan Tunç ${ }^{2}$ \\ ${ }^{1}$ National Education Directorate, Siirt, Turkey \\ ${ }^{2}$ National Education Directorate, Diyarbakır, Turkey
}

Copyright $\bigcirc 2018$ by authors, all rights reserved. Authors agree that this article remains permanently open access under the terms of the Creative Commons Attribution License 4.0 International License

\begin{abstract}
This study was carried out to investigate the digital addiction (DA) level of the university students according to their purposes for using digital tools. 527 students studying at the faculties of education of Erzincan, Dicle, and Siirt Universities participated this study in which general survey model was used. A form was used to reveal for which purpose and how often the students used digital tools. The DA levels of the students were found out by the Digital Addiction Scale. According to the frequencies of the students' using digital tools for participating social media, playing games, communicating, and shopping, the DA scores were found to differ significantly for those who used digital tools for these purposes more frequently. The DA scores of the students who used digital tools a lot for research were significantly lower than the scores of the students using tools less for this purpose. It was also found that the DA scores of the students who used digital tools for watching films and listening to music with different frequencies did not differ from each other significantly. The study has shown that while the frequent use of digital tools for participating social media is highly effective on digital addiction, the frequent use of digital tools for games, communication, research, and shopping has a low effect on digital addiction.
\end{abstract}

Keywords Addiction, Behavioral Addiction, Digital Addiction

\section{Introduction}

History investigates human history by dividing it into several periods. Each period has its own characteristics and differentiates from other periods with these characteristics. It has been accepted by many scholars that humanity is in a new period today. The most certain characteristic of this new period is the developments in technology and their effects on human life. The developments in technology led to experiencing the process of digitalization [1]. Digital tools are used commonly in education, media, trade, child games, librarianship services, culture and art, communication, public services and so on now. Therefore, the period in which we live is called digital era. $[1,2,3,4$, $5,6,7,8,9]$.

The developments in information technologies have led to the production of such tools as mobile phone, desktop computer, laptop computer, smart TV, and tablet, and to marketing them with a low price. In addition, the developments on the Internet have changed the perceptions of time, space, and distance by speeding information exchange and helped to do a lot of work and operations with digital tools easily. As a result of this, these technological devices have started to be used commonly at home and work $[10,11]$. According to a study made in Turkey, it was found out that \% 96.9 of the houses had mobile or smart phone, $\% 22.9$ of them had desktop computer, \%36.4 of them had laptop computer, and \% 29.6 of them had tablet computer in April, 2016. In the same study, it was revealed that $\% 76.3$ of the houses had the opportunity of accessing the Internet [12].

Digital tools save time by easing human life, make quick access to information possible, and help to spend time enjoyably. However, the overuse of digital tools causes several problems. These problems named as addiction lead to physiological and psychological problems among children and the youth [13].

Addiction is defined as impulse dependent on a habit of a certain activity or substance use though it has destructive effects on the physical, social, emotional, and mental health of the individual as well as his/her financial situation [14]. While the addictions like alcohol, cigarette, drug addictions, and etc. are defined as "substance addiction", 
the addictions such as gambling, doing sports excessively, spending time with digital tools overmuch, and etc. are classified as "behavioral addiction". Behavioral addiction is a type of addiction which arises because of the frequent repetition of a habit without being dependent on any substance, where the pathological problems seen in substance addiction are observed, and in which the individual goes on doing the behavior though he/she recognizes that he/she is affected $[15,16,17]$.

It has been found that a lot of factors have effects on behavioral addiction. According to this, some individuals are genetically more inclined to have behavioral addiction. Psychological factors like depression and social anxiety, and social factors like poor family support and social relations also influence behavioral addiction [18]. A lot of criteria have been put forward to consider an individual as a behavioral addict in the literature. In this issue, Griffiths mentioned that a behavior or activity should exhibit the characteristics below to be considered as a behavioral addiction [19]

1. Salience: That an action becomes attention-grabbing in terms of an individual's life.

2. Mood modification: That the action affects the individual's mood.

3. Tolerance: The increase in the amount of the repetition of the action to show the effect it creates on the individual.

4. Withdrawal: The observable unpleasant emotions or physical symptoms occurring when the action is interrupted.

5. Conflict: The conflict and interference between the individual and the people around him/her that occur in him/her depending on the action.

6. Relapse: That a certain action tends to occur again after the avoidance or control lasting long years.

The developments in the digital software cause new types of behavioral addiction to arise. Digital game addiction and Facebook addiction are the examples of these new types [20,21]. Besides, new devices compatible with digital technology are developed, and new types of addictions enter the literature. Smart phone addiction is an example of this [22]. The fast developments in technology indicate that new types can be added to the types of addiction in this scope.

DA is a concept including game, social networking, smart phone, the Internet addictions, and etc. [23, 24]. According to this, DA can be defined as impulse which leads to going on using digital tools although it is known that overusing such tools will create physical, emotional, mental, and social problems for an individual. It is seen that several studies on DA have been made abroad recently. DA is also a serious problem for the youth in Turkey. Only the opening of the polyclinics to treat the individuals with DA is the biggest evidence of this [25]. Consequently, it is important to investigate DA in its different aspects to protect the youth and children from its negative effects.
The aim of this study is to investigate the DA levels of the university students according to the frequency of their use of digital tools for participating social media, playing games, learning information, watching films - listening to music, doing shopping, or communicating (MSN, e-mail, etc.). Hence, the study tries to reveal which use of digital tools is more effective on DA.

\section{Materials and Methods}

General survey model was used in this study. It is a survey model used in a crowded population for making a judgment about the population [26].

\subsection{Population and Sample}

The students studying at the faculties of education of Erzincan, Siirt, and Dicle Universities in the spring term of the 2015-2016 education year constituted the population of the study. 527 students chosen from the population randomly formed the sample of the study. The sample included 196 students (95 females, 74 males) from Siirt University, 157 students (99 females, 58 males) from Dicle University, and 201 students (140 females, 61 males) from Erzincan University. Most of the participants, studying in the east part of Turkey, are from low or middle class families, and they are said to be conservatives.

\subsection{Data Collection Tools}

The frequency of the participants' use of digital tools according to their purposes for using tools was found with the information form depending on their perceptions. Their DA levels were determined with the Digital Addiction Scale (DAS).

\section{The Digital Addiction Scale}

The DAS is a five-point, nineteen-item Likert-type scale. It has five sub-dimensions: Overuse, Non-restraint, Inhibiting the Flow of Life, Emotional State, and Dependence. Its Cronbach's Alpha coefficient was calculated 0.874. The scale was found to explain the $\% 59.51$ of variance. As a result of the confirmatory factor analysis, the values of $\chi^{2} /$ sd., RMSEA, NFI, CFI, IFI, and RMR were $2.326,0.05,0.90,0.94,0.94$, and 0.058 successively. The coefficient of the test-retest reliability made in a three-week interval was $r=.779(p<.001)$. The DA point is obtained by dividing the total point from the DAS by 19 [27].

\subsection{Limitations}

In literature, it can be seen that there are a lot of purpose of digital device use that might cause DA. Present study focuses on only the use of digital devices by means of social network, game, research, film-music, shopping and 
communication. To contribute the literature accurately, the cultural features of the participants are taken into consideration. From this point of view, for sexuality and gambling purpose of digital devise use are not included in the study. Hence, participants are enabled to feel comfortable and answer the accurately.

\subsection{Data Collection Procedure and Data Analysis}

The data were collected by the faculty members within their class times depending on voluntariness and analyzed with SPSS. It was determined with the Kolmogorov-Smirnov test that the DA points distributed normally on the basis of the frequencies of use of digital tools according to each purpose of using tools ( $p>05$ ). Due to this, the averages of the points were compared with one-way analysis of variance. The homogeneity of the groups was determined with the Levene test $(p>.05)$. One of the Post-hoc tests, the Scheffe test was used to find out from which group the difference resulted. The effect size of the study was calculated with $\eta 2$. The $\eta 2$ value was determined as small, medium, and large at the levels of $.01, .06$, and.14 respectively [28]. The differences were considered to be statistically significant at the 0.05 level.

\section{Findings}

The DA points of the university students depending on the frequency of their use of digital tools for participating social networks, playing games, learning information (research), watching films - listening to music, doing shopping, and communicating (MSN, e-mail, etc.) were compared with one-way analysis of variance. The results are shown in Table 1.

As seen in Table 1, a statistically significant difference was found between the DA points of the university students according to the frequency of participating social networks $(p<.05)$. It was determined that the difference was between the groups using digital tools for participating social networks more often. Participating social networks was found to have a big effect on the DA points.

The results of the analysis indicated that there was a significant difference between the DA points of the students in terms of using digital tools for playing games $(p<.05)$. It was found out that differentiation existed between the group of the students who played games a lot with digital tools and the group of the students who never played games (for the group playing games a lot). Playing games was determined to have little effect on the DA points.

Table 1. The results of the one-way analysis of variance of the DA points depending on the frequency of the use of digital tools

\begin{tabular}{|c|c|c|c|c|c|c|c|c|}
\hline Purpose & Frequency & $\mathbf{N}$ & $\overline{\mathbf{x}}$ & ss. & $\mathbf{F}$ & $\mathbf{p}$ & Post Hoc & $\eta 2$ \\
\hline \multirow{3}{*}{ Social Network } & Never $^{1}$ & 59 & 2.42 & 0.66 & \multirow{3}{*}{55.085} & \multirow{3}{*}{0.000} & $\mathrm{p}=0.110(1-2)$ & \multirow{3}{*}{0.174 (Large) } \\
\hline & Little $^{2}$ & 233 & 2.68 & 0.58 & & & $\mathrm{p}=0.000(1-3)$ & \\
\hline & $\mathrm{A} \operatorname{lot}^{3}$ & 233 & 3.15 & 0.57 & & & $\mathrm{p}=0.000(2-3)$ & \\
\hline \multirow{3}{*}{ Game } & Never $^{1}$ & 158 & 2.74 & 0.67 & \multirow{3}{*}{8.111} & \multirow{3}{*}{0.000} & & \multirow{3}{*}{0.030 (Small) } \\
\hline & Little $^{2}$ & 282 & 2.86 & 0.64 & & & $\mathrm{p}=0.000(1-3)$ & \\
\hline & $\mathrm{A} \operatorname{lot}^{3}$ & 87 & 3.08 & 0.56 & & & & \\
\hline \multirow{3}{*}{ Research } & Never $^{1}$ & 17 & 3.05 & 0.53 & \multirow{3}{*}{5.280} & \multirow{3}{*}{0.005} & & \multirow{3}{*}{0.019 (Small) } \\
\hline & Little $^{2}$ & 252 & 2.94 & 0.62 & & & $\mathrm{p}=0.011(2-3)$ & \\
\hline & $\mathrm{A} l \operatorname{lot}^{3}$ & 256 & 2.77 & 0.66 & & & & \\
\hline \multirow{3}{*}{ Film-Music } & Never $^{1}$ & 17 & 2.77 & 0.77 & \multirow{3}{*}{2.736} & \multirow{3}{*}{0.066} & & \\
\hline & Little $^{2}$ & 154 & 2.77 & 0.65 & & & & \\
\hline & $\mathrm{A} \operatorname{lot}^{3}$ & 355 & 2.91 & 0.65 & & & & \\
\hline \multirow{3}{*}{ Shopping } & Never $^{1}$ & 152 & 2.84 & 0.65 & \multirow{3}{*}{6.859} & \multirow{3}{*}{0.001} & $\mathrm{p}=0.027(1-3)$ & \multirow{3}{*}{0.025 (Small) } \\
\hline & Little $^{2}$ & 257 & 2.79 & 0.66 & & & $\mathrm{p}=0.001(2-3)$ & \\
\hline & ${\mathrm{A} l o t^{3}}^{3}$ & 116 & 3.05 & 0.56 & & & & \\
\hline \multirow{3}{*}{ Communication } & Never $^{1}$ & 47 & 2.71 & 0.71 & \multirow{3}{*}{9.151} & \multirow{3}{*}{0.000} & $\mathrm{p}=0.042(1-3)$ & \multirow{3}{*}{0.033 (Small) } \\
\hline & Little $^{2}$ & 189 & 2.73 & 0.63 & & & $\mathrm{p}=0.000(2-3)$ & \\
\hline & $\mathrm{A} \operatorname{lot}^{3}$ & 291 & 2.97 & 0.63 & & & & \\
\hline
\end{tabular}


The difference between the DA points of the students depending on the frequency of using tools for research was found to be statistically significant $(p<.05)$. The points of the students using digital tools for research little were significantly higher than the averages of the points of the students using tools for research a lot. The study showed that the use of digital tools for research had little effect on the DA points.

Any significant difference was not found between the DA points of the students according to the frequency of using digital tools for entertainment like watching films listening to music ( $\mathrm{p}>0.05$ ).

According to the frequency of using digital tools for doing shopping, the DA points of the students differed from one another significantly $(\mathrm{p}<.05)$. The DA points of the students using digital tools for doing shopping more were determined to be significantly higher than the DA points of the students using digital tools for shopping little and never using tools for this purpose. The use of digital tools for doing shopping was found to have little effect on the DA points.

Depending on the frequency of using digital tools for communication, the differentiation between the DA points of the students was statistically significant $(p<.05)$. The differentiation existed between the groups using digital tools for communication more often. The use of digital tools for communicating was found out to have little effect on the DA points.

\section{Discussion and Conclusion}

It was found in the study that the DA points of the students using digital tool for participating social networks a lot were significantly higher than the points of the students using tools for this purpose little and not using tools for this, and the points of the students using tools for this purpose little were significantly higher than the points of the students not using tools for this. There are several studies supporting this result in the literature $[29,30,31$, 32]. Participating social networks was determined to have a big effect on DA. This situation can be explained with the psychological attraction of social networks and moral panic. Social networks are an online platform where the individuals can build profile, make friendships, express themselves in real life without being censored, mask themselves if they want, and feel more comfortable, and which is freer than other media tools [33, 34]. Joining social networks provides an opportunity to the participants living in a conservative society to express their ideas and thoughts, that they cannot express in real life, freely and without any pressure in virtual environment, so they can be tempting for students. That might cause participants to visit social websites more often. In addition, an individual can make a two-way communication with other individuals whom he/she knows or does not know. This situation creates pleasant emotions for him/her [55]. These characteristics make social networks psychologically attractive. On the other hand, moral panic can be defined as societal reaction to a person, event, or situation that is in conflict with the common values and benefits of the society. Social networks can keep the anxiety and fear arising because of a situation against the society's common values on the agenda with online interaction. Moral panic reactions to the issues like nationalism, violence to women, child abuse, fashion, and etc. may be one of the reasons why students want to use social networks more $[35,36,37$, $38,39,40,31]$.

The study showed that the DA points of the participants using digital tools for playing games a lot were significantly higher than the points of the other participants. Even though digital games have positive characteristics like tension release, reviving one's imagination, and etc., they may lead to addiction when the individual spends time with them excessively $[41,42]$. Lemmens and colleagues defined digital game addiction as "that the individual goes on using computer games excessively and obsessively though this situation causes social and/or emotional problems" [43]. They revealed that there was a positive and low-level relationship between the Internet addiction and time spent on playing games. Besides, they showed that the time the Internet addict adults spent on playing games was significantly higher than the time the adults who were not the Internet addicts spent [32]. This result supports the finding of this study. This study indicated that the use of digital tools for playing games had little effect on the DA levels. Problematic game playing was found to be common among the teenagers between 10 and 19 years old in other studies [54]. According to this, using digital tools for playing games is thought to be more effective on teenagers than on university students since the use of digital tools for playing games is preferred by teenagers more.

Information can be recorded, produced, shared, and accessed through digital tools today. Online libraries, computer-aided educational software, digital lesson materials, online university, and search engines are the concrete products of the change experienced [44]. It can be said that this situation has made the use of digital tools by university students for learning information obligatory. It was revealed in this study that the DA points of the students using digital tools for research little were significantly higher than the points of the students using digital tools for this purpose a lot. This situation can be explained by the fact that the students using digital tools for research a lot are good users of digital tools. There are several studies supporting this explanation in the literature. Those studies pointed out that the use of the Internet for social media and entertainment was more effective on the Internet addiction than the use of it for research [45]. They also found out that there was no statistically significant difference between the time spent on the Internet for research by the Internet addict young adults and by the ones who were not addicts [32]. 
They revealed that the problematic Internet use points of the university students using the Internet for learning information were lower than the points of the students who used it for having fun and building social relationship [46].

Technological developments have caused changes in people's shopping habits and provided them with the opportunity of doing online shopping. Online shopping is a kind of e-commerce which enables customers to buy goods or services online [47]. The factors like cost, economical factors, time, usefulness (product and model range), and entertainment make online shopping attractive [48]. In this situation, online shopping becomes an uncontrollable behavior for some individuals [49]. The problems leading to the repetition personal and familial troubles depending on extreme impulse shopping are called compulsive buying disorder [50]. The amount of online shopping in Turkey tends to increase. The amount of shopping done on the Internet was $\% 30,8$ of the total amount of shopping done in the country in 2014, \%33,1 in 2015, and \%34,1 in 2016 [51]. This study demonstrated that the DA points of the students using digital tools for shopping were significantly higher than the points of the students using tools for shopping little and not using them for this purpose. Similarly, the DA points of the students using digital tools for this purpose little were found to be significantly higher than the points of the students not using tools for this. Another study in the literature indicated that there was not significant difference between the problematic Internet use points of the students doing shopping on the Internet and of the ones who did not do so [45]. This result conflicts with the finding of this study. This study showed that the use of digital tools for shopping had little effect on DA. This situation can be explained by the fact that shopping was not attractive a lot for the participants because they were students and had the economic self-sufficiency only to meet their basic needs. Hence, Okay revealed that the university students used the Internet for shopping least [52]. However, the use of digital tools for shopping may have the potential to trigger DA because the increase in the frequency of using tools for this purpose rises the DA level, and the amount of doing online shopping is constantly increasing.

In the study, there was not found to be any significant difference between the DA points of the students according to the use of digital tools for watching films and listening to music. This situation can be explained with the students' preferences of use. Yet, some studies demonstrated that the rate of the university students' use of the Internet for watching film - listening to music was lower than the rates of their Internet use for other purposes [53], while it was found to be high in some other studies [52]. Therefore, this finding can be commented like that university students could control themselves in using digital tools for entertainment purposes like watching film and listening to music, so the use of digital tools for such purposes did not have a direct effect on DA.
Communication can be made virtually, message can be sent instantly, and information and documents can be transferred through digital tools [44]. University students use digital tools for this purpose a lot $[52,53]$. The study demonstrated that the DA points of the students using digital tools for communication were significantly higher than the ones of the students using tools for this purpose little, while the points of the students using tools for communication little were higher than the ones of the students who never used tools for this purpose. Supporting this finding, Morrison and Gore revealed that there was a significant difference between the time spent on the Internet for communication by the Internet addict adults and by the ones who were not Internet addicts [32]. They also found that there was a significant low-level relationship between the averages of the Internet addiction points and the time spent for communication. It is thought that the use of digital tools for communication because of the reasons like the loyalty to friends or family may lead to problematic digital tool use among students. Though digital tools were used for communication a lot, they were determined to have little effect on DA in this study. The obligation that the sender and receiver must be ready at the same time to communicate can avoid the continuity of communication. This restricts students to using digital tools whenever they want, so it causes this purpose of using digital tools to have little effect on DA.

Depending on the results of this study, it was found out that the use of digital tools participating social network, especially students from low or middle class, they are believed to be conservatives, was very effective on DA, while the use of digital tools for games, research, communication, and shopping had little effect on DA. The use of tools for watching films and listening to music was found not to have any effect on DA. Based on the result of present study, following suggestion is made.

Short-term suggestions: Conferences, seminar and similar occasions about DA should be organized at universities. There should be agencies to assist and guide students who have DA problems.

Long-term suggestions: Students should be educated about how to use digital tools from early ages, so they can control themselves in using digital tools and become good digital tool users. For this purpose, right use of digital device use should be included in the primary and secondary school curriculums. Also, parents should be enabled training programmes about this topic. Moreover, videos about DA can be prepared and broadcasted on TVs in order to inform society and arise awareness. Students should be encouraged to do sports and have hobbies in order to benefit from their free time by keep themselves away from digital tools. That future studies should be made about under which trend topic university students spend time, which trend topics they find more attractive, and how these two will affect DA is thought to be useful. 


\section{REFERENCES}

[1] Kaplan K, Ertürk E. Digital age and ideological devices of the individual. The Turkish Online Journal of Design, Art and Communication - TOJDA 2012; 2(4).

[2] Frrat M. Digital topic maps as a customizable e-learning tool. International Journal of Informatics Technologies 2009; 2(3).

[3] Kanat S. Digital media and war from the perspective of international relations approaches. Digital Media 2016; 1(2): $528-546$

[4] Yumuşak İG. The effects of electronic commerce on developing countries and an evaluation on Turkey. Available from

http://econwpa.repec.org/eps/mac/papers/0404/0404032.pdf Available on January 28, 2017.

[5] Kneer J, Rieger D, Ivory JD, Ferguson C. Awareness of risk factors for digital game addiction: interviewing players and counselors. International Journal of Mental Health and Addiction 2014; 12(5): 585-599.

[6] Afzali M. The hybrid library: The focal point of traditional and digital. Turkish Librarianship 2008; 22(3): 266-278.

[7] Çokokumuş B. Art and culture on digital media. International Journal of New Trends in Arts, Sports \& Science Education (IJTASE) 2012; 1(3), 51-66.

[8] Vural ZBA, Bat M. Social media as a new communication enviroment: a research on Ege University Faculty of Communication. Journal of Yasar University, 2010, 20(5), 3348-3382.

[9] Çukurçayır MA, Çelebi E. Informatıon society and Turkey in the process of implementing e-government 2009; 5(9): $59-82$.

[10] Temel F, Önürmen O, Köprü M. Digital means and the internet during electoral campaigns: A case study on university students. Global Media Journal: Turkish Edition 2014; 5(9).

[11] Balay R. Globalization, information society and Education. Ankara University, Journal of Faculty of Educational Sciences 2004; 37(2), 61-82

[12] TÜIKK. Household information technology research. Available from http://www.tuik.gov.tr/PreHaberBultenleri.do?id=21779. Available on June 4, 2017.

[13] Arslan A, Kırık, AM, Karaman M, Çetinkaya A. Digital addiction in high school and university students. International Peer-Reviewed Journal of Communication And Humanities Research 2015; 8(8): 34-58.

[14] Young KS, Yue XD, Ying L. Prevalence estimates and etiologic models of Internet addiction. Internet addiction: A handbook and guide to evaluation and treatment 2011;3-17.

[15] Kır İ, Sulak Ş. Determining internet addiction level of faculty of education students. Electronic Journal of Social Sciences 2014; 13(51).

[16] Gününç S, Kayri M. The profile of internet dependency in Turkey and development of internet addiction scale: Study of validity \& reliability. Hacettepe University Journal of
Education 2010; 39(39): 220-232.

[17] You S, Kim E, Lee D. Virtually real: Exploring avatar 1 dentification in game addiction among. Games and Culture 2007; 12(1): 56-71

[18] Chang JPC, Hung CC. Problematic internet use. IACAPAP e-Textbook of Child and Adolescent Mental Health. Geneva: International Association for Child and Adolescent Psychiatry and Allied Professions 201; 2.

[19] Griffiths, M. Internet Addiction: Fact or Fiction? The Psychologist, 12(5), 246-250. (Trans.: K. Alat), Turkish Psychological Bulletin 1999. ISSN: 1300-7408. Available from:http://www.isgucdergi.org/?p=article\&id=39\&cilt=5 \&sayi=1\&yil=2003. Available on September 15, 2016.

[20] Yalçın IA, Erdoğan S. Validity and reliability of the Turkish version of the Digital Game Addiction Scale. Anatolian Journal of Psychiatry 2015; 16(Special issue.1):10-18.

[21] Çam E. Educational and general use of Facebook and facebook addiction of teacher candidates (SAU College of Education Sample) (Unpublished Master's Thesis), University of Sakarya: Sakarya, 2012.

[22] Noyan CO, Enez Darçın A, Nurmedov S, Yılmaz O, Dilbaz N. Validity and reliability of the Turkish version of the Smartphone Addiction Scale-Short Version among university students. Anatolian Journal of Psychiatry 2015; 16(Special issue.1):73-81.

[23] Jiang J, Phalp KT, Ali R. Digital addiction: Gamification for precautionary and recovery requirements, 2015. Available from

http://eprints.bournemouth.ac.uk/21887/1/04-Posters.pdf. Available on May 15, 2017.

[24] Cover R. Digital addiction: The cultural production of online and video games junkies media. International Australia Incorporating Culture and Policy 2004; 113,110-123

[25] Social media. Available from http://sosyalmedya.co/bakirkoy-internet-bagimliligi-polikli nigi/, Available on January 31, 2016.

[26] Karasar N. Bilimsel araştırma yöntemi (Scientific research method). Ankara: Nobel, 2014.

[27] Kesici A, Tunç NF. The development of the Digital Addiction Scale for the university students: Reliability and validity study. Universal Journal of Educational Research 2018; 6(1): 91-98. DOI: 10.13189/ujer.2018.060108

[28] Can A. SPSS ile bilimsel araştırma sürecinde nicel veri analizi (Quantitative data analysis in scientific research process with SPSS) (3. ed.). Ankara: Pagem Akademi, 2014.

[29] Segal, NK, Gofarth AN, Bowman N, Pham A. Social network practices in school psychology: Have moral panic concerns been over started? Journal of Applied School Psychology 2016; 32 (1), 66-81.

[30] Toraman M. Investigation of the relationship of secondary school students' academic achievement with internet addiction and social networking use levels (Unpublished Master's Thesis). University of Firat: Elazı $\breve{g}, 2013$.

[31] Y1ldız S, Sümer HH. Media and moral panic. Erciyes Üniversitesi İletișim Fakültesi Dergisi (Erciyes University, Journal of Faculty of Communication) 2010; 1(3),35-46 
[32] Morrison CM, Gore H. The relationship between excessive Internet use and depression: a questionnaire-based study of 1,319 young people and adults. Psychopathology 2010; 43(2), 121-126.

[33] Greenfield DN. Psychological characters of compulsive internet use: A preliminary analysis. Cyberpsychology \& Behavior 1999; 2(2); 403-412.

[34] Kuss DJ, Griffiths MD. Online social networking and addiction-a review of the psychological literature. International Journal of Environmental Research and Public Health 2011; 8(9), 3528-3552.

[35] Akdemir N. Social media mobility on the basis of media and communication; "Nationalism" and "hate speech". Available from

"https://scholar.google.com.tr/scholar?hl=tr\&q=Medya+ve $+\% \mathrm{C} 4 \%$ B0leti $\% \mathrm{C} 5 \% 9$ Fim+Temelinde+Sosyal+Medya+Ha reketlili $\% \mathrm{C} 4 \% 9 \mathrm{Fi} \% 3 \mathrm{~B}+\% \mathrm{E} 2 \% 80 \% 9 \mathrm{CMilliyet} \% \mathrm{C} 3 \% \mathrm{~A} 7 \mathrm{ili}$ $\mathrm{k} \% \mathrm{E} 2 \% 80 \% 9 \mathrm{D}+\mathrm{ve}+\% \mathrm{E} 2 \% 80 \% 9 \mathrm{CNefret}+\mathrm{S} \% \mathrm{C} 3 \%$ B6ylem $\mathrm{i} \% \mathrm{E} 2 \% 80 \% 9 \mathrm{D} .+\& \mathrm{btnG}=\& 1 \mathrm{r}="$ Available on December 12 , 2016 .

[36] Dwyer R, Fraser S. Addiction via hashtags: How is twitter making addiction? Contemporary Drug Problems 2016; 43(1), 79-97.

[37] Macintosh A. The emergence of digital governance. Significance 2008; 5(4), 25-48.

[38] Marwick AE. To catch a predator. the my space mirak panic. firs monday peer. Reviewed Journal on The Internet 2008; 13(6)

[39] McRobbie A, Thorntom SL. Rethinking' moral panic for multi-mediated social worlds. The British Journal of Sociology 1995; 46(4),559-574

[40] Şenol O. A Research on investigation of internet using purposes of technical teacher candidates. Electronic Journal of Machine Technologies 2010; 7(1):97-109.

[41] Özkan M, Solmaz B. Mobile addiction of generation Z and its effects on their social lives. Procedia Social and Behavioral Sciences 2015; 205: 92-98.

[42] Kim D, Lee Y, Lee J, Nam J, K, Chung Y. (2014). Development of Korean smartphone addiction proneness scale for youth. Plos One 2014; 9(5):1-8.

[43] Lemmens JS, Valkenburg PM, Peter J. Development and validation of a game addiction scale for adolescents. Media Psychology 2009; 12(1): 77-95.
[44] Cakır H, Nursel Y. The virtual classroom of system that using internet and intranet. Kastamonu Education Journal 2006; 14(1): 101-112.

[45] Tekinarslan E, Gürer MD. Problematic Internet use among Turkish university students: A multidimensional investigation based on demographics and Internet activities. International Journal of Human Sciences [Online]. 2011; 8:1

[46] Ceyhan AA. University students' problematic internet use and communication skills according to the internet use purposes. Educational Sciences: Theory and Practice 2011;11(1):69-77.

[47] Sequeira JP. A Study on e-shopping trends in metropolitan cities of India with special reference to Bangalore City. The International Journal of Business \& Management 2015; 3(7), 50 .

[48] Günüç S, Doğan Keskin A. Online shopping addiction: Symptoms, causes and effects. Addicta: The Turkish Journal on Addictions 2016; 3(3), 339-364. DOI 10.15805/addicta.2016.3.0104

[49] Lejoyeux M, Mathieu K, Embouazza H, Huet F, Lequen V. Prevalence of compulsive buying among customers of a Parisian general store. Comprehensive Psychiatry 2007; 48(1), 42-46.

[50] Clark M, Calleja K. Shopping addiction: A preliminary investigation among Maltese university students. Addiction Research \& Theory 2008; 16(6), 633-649.

[51] TÜİK. Household information technology research. Available from: http://www.tuik.gov.tr/PreHaberBultenleri.do?id=21779. Available on June 4, 2017.

[52] Senol FT. Moral Panic Reaction in Social Media: "TC (Republic of Turkey)" Organization in Facebook. Global Media Journal: TR Edition 2014; 4(8), 276-304.

[53] Gümüş AB, Şıpkın S, Tuna A, Keskin G. The relationship between problematic internet use, violence trend and some demographic variables among university students. TAF Preventive Medicine Bulletin 2015; 14(6):460-467.

[54] Irmak AY, Erdoğan S. Digital game addiction among adolescents and younger adults: A current overview. Turkish Journal of Psychiatry 2016; 27(2).

[55] Güney B. Digital culture transition in digital addiction: Netlessphobia. e-Journal of New Media, 2017;1(2):207-213. 